\title{
Retraction
}

Line Brandt ${ }^{1}$

\section{Retraction of: The rhetorics of fictive interaction in advertising: The case for imagined direct speech in argumentation}

${ }^{1}$ Independent Scholar, Lund, Denmark, E-mail: cogsemlb@yahoo.com

DOI: 10.1515/cogsem-2018-0008

Retraction of: Brandt, Line. November 2016. The rhetorics of fictive interaction in advertising: The case for imagined direct speech in argumentation. Volume 9(2), pages 149-182. (DOI: https: / doi.org/10.1515/cogsem-20160006).

This article has been withdrawn due to copyright infringement of the article Brandt, Line \& Esther Pascual. 2016. "Say hello to this ad" - The persuasive rhetoric of fictive interaction in marketing". In Esther Pascual and Sergeiy Sandler (eds.), The Conversation Frame. Forms and functions of fictive interaction, 303-322. Amsterdam: John Benjamins. 